\title{
Characterization of commercial Tunisian monovarietal olive oils produced from autochthonous olive cultivars
}

\author{
Souihli Slim ${ }^{1,2}$, Nuno Rodrigues ${ }^{1,3}$, Ana C. A. Veloso ${ }^{4,5}$, Luís G. Dias ${ }^{1}$, Rebeca Cruz ${ }^{6}$, Susana Casal ${ }^{6}$, \\ Souheib Oueslati ${ }^{2}$, José A. Pereira ${ }^{1}$, António M. Peres ${ }^{1,7 *}$ \\ ${ }^{1}$ Centro de Investigação de Montanha (CIMO), ESA, Instituto Politécnico de Bragança, Campus de Santa Apolónia, 5300-253 Bragança, \\ Portugal, ${ }^{2}$ Institut Préparatoire aux Etudes Scientifiques et Techniques (IPEST), Laboratoire Materiaux, Molécules et Applications (LMMA), \\ BP 51, 2070LaMarsa, Tunisia, ${ }^{3}$ Universidad de Léon, Departamento de Ingeniería Agrária, Av. Portugal, $n^{\circ} 41,24071$ Léon, Spain, ${ }^{4}$ Instituto \\ Politécnico de Coimbra, ISEC, DEQB, Rua Pedro Nunes, Quinta da Nora, 3030-199 Coimbra, Portugal, ${ }^{5}$ CEB - Centre of Biological \\ Engineering, University of Minho, Campus de Gualtar, 4710-057 Braga, Portugal, ${ }^{6}$ REQUIMTE, Laboratory of Bromatology and Hydrology, \\ Faculty of Pharmacy, University of Porto, Rua de Jorge Viterbo Ferreira, 228, 4050-313 Porto, Portugal, 'Laboratory of Separation and \\ Reaction Engineering - Laboratory of Catalysis and Materials (LSRE-LCM), ESA, Instituto Politécnico de Bragança, Campus Santa Apolónia, \\ 5300-253 Bragança, Portugal
}

\section{A B S TR A C T}

Tunisian commercial monovarietal olive oils, produced from two predominant autochthonous olive cultivars (cvs Chétoui and Oueslati) and another less investigated olive cultivar (cv Sahli) were studied. Chemical and sensory data have shown that most olive oils should be classified as lampante olive oil, pointing out the need of improving producing and/or storage conditions. Sahli olive oils showed the lowest total phenols content $(157 \pm 48 \mathrm{mg} / \mathrm{kg})$, oxidative stability $(6.5 \pm 2.1 \mathrm{~h})$, DPPH scavenging activity $(68 \% \pm 14)$ and monounsaturated fatty acids content $(63.1 \% \pm 3.1)$. These olive oils had the highest saturated and polyunsaturated fatty acids contents $(19.9 \% \pm 2.4$ and $16.9 \% \pm 1.4)$ as well as total tocopherols levels $(222 \pm 49 \mathrm{mg} / \mathrm{kg})$. Finally, the information of 12 selected parameters (total phenols, oxidative stability, nine fatty acids and $\gamma$-tocopherol), allowed establishing a linear discriminant model that correctly classified olive oils according to the olive cultivar with predictive rates of $90 \% \pm 8$. Heptadecenoic, behenic and eicosenoic acids were the three fatty acids identified as the most relevant chemical markers of Sahli olive oils.

Keywords: Chemometrics; Fatty acids profile; Quality Physico-chemical parameters; Tocopherols profile; Tunisian olive oil

\section{INTRODUCTION}

Tunisia is the second largest olive oil exporter and producer after the European Union holding a high number of autochthonous olive cultivars (Dabbou et al., 2015; Essid et al., 2016; Hlima et al., 2017). Chemlali and Chétoui are the two predominant olive cultivars, while the others have a lower importance and more limited geographical implementation (Issaoui et al., 2007; Tena et al., 2007; Baccouri et al., 2008; Dabou et al., 2011). Indeed, the majority of the studies on Tunisian olive oils reported the biochemical and/or sensory characterizations of extra virgin or virgin olive oils (EVOO, VOO) produced from those two main Tunisian olive cultivars: cv Chemlali (Dhi et al., 2004; Issaoui et al., 2007; Tena et al., 2007; Dabbou et al., 2009; Guerfel et al., 2009; Kotti et al.,
2009; Taamalli et al., 2010; Youssef et al., 2011; Hassine et al., 2015; Laroussi-Mezghani et al., 2015; Mansour et al., 2015; Abdalah et al., 2016a, 2016b; Bazakos et al., 2016; Fares et al., 2016; Gargouri et al., 2016, Hlima et al., 2017) or cv Chétoui (Dhi et al., 2004; Temine et al., 2006; Issaoui et al., 2007; Tena et al., 2007; Haddada et al., 2008; Dabbou et al., 2009; Guerfel et al., 2009; Kotti et al., 2009; Taamalli et al., 2010; Youssef et al., 2011; Issaoui et al., 2012; Hassine et al., 2015; Laroussi-Mezghani et al., 2015; Bazakos et al., 2016; Essid et al., 2016; Gargouri et al., 2016;Laroussi-Mezghani et al., 2016; Hlima et al., 2017; Loubiri et al., 2017). However, the commercialization of olive oils with different and unique sensory and nutritional characteristics is gaining importance (Baccouri et al., 2008), leading to the chemical assessment of Tunisian olive oils produced from other minor autochthonous

\section{${ }^{*}$ Corresponding author:}

António M. Peres, Centro de Investigação de Montanha (CIMO), ESA, Instituto Politécnico de Bragança, Campus de Santa Apolónia, 5300-253 Bragança, Portugal. E-mail: peres@ipb.pt

Received: 21 March 20108; $\quad$ Accepted: 01 July 2018 
olive cultivars such as cv Oueslati (Krichene et al., 2007; Dabbou et al., 2009; Dabbou et al., 2010; Taamalli et al., 2010; Youssef et al., 2011; Hassine et al., 2015; Laroussi-Mezghani et al., 2015; Bazakos et al., 2016; Fares et al., 2016; Laroussi-Mezghani et al., 2016; Ouni et al., 2016). Occasionally, other Tunisian autochthonous olive cultivars have also been characterized (e.g. cvs Chemchali, Dhokar, Fouji, Jeddaria, Jemri, Neb Jmal, Sahli, Zalmati and Zarrari) (Issaoui et al., 2007; Dabbou et al., 2010; Hassine et al., 2015; Laroussi-Mezghani et al., 2015; Mansour et al., 2015; Abdalah et al., 2016a; Bazakos et al., 2016; Loubiri et al., 2017; Hlima et al., 2017; Mohamed et al., 2018a). Only one work has reported the study of extra-virgin Tunisian olive oils produced with olives from cv Sahli, grown in Sfax National Collection (South of Tunisia), thus under the same edaphoclimatic conditions (Issaoui et al., 2007). The above mentioned works showed that the contents of several quality and compositional parameters (such as: free acidity (FA), peroxide values (PV), $K_{232}$ and $K_{270}$ spectrophotometric indexes, oxidative stability(OS), antioxidant activity, total phenols and tocopherols, fatty acids profiles and volatile compounds) of edible Tunisian olive oils (i.e., EVOO and VOO) are highly dependent on the olive cultivar. Some works have also focused on the discrimination of Tunisian olive oils according to olive cultivar, geographical origin or maturity index, using chemical data such as the fatty acids, phenolic compounds (Mohamed et al., 2018a) and/or tocopherols profiles (Guerfel et al., 2009; Kotti et al., 2009; Taamalli et al., 2010; LaroussiMezghani et al., 2015; Abdalah et al., 2016a, 2016b; Laroussi-Mezghani et al., 2016; Mohamed et al., 2018b) or electrochemical fingerprints recorded using electronic noses or electronic tongues (Tena et al., 2007; Slim et al., 2017; Souayah et al., 2017; Marone et al., 2018). In this work, commercial monovarietal Tunisian olive oils, randomly selected to mimic a practical situation that may occur when a typical consumer is purchasing this kind of food product at a supermarket, were evaluated taking into account the chemical and organoleptic parameters. Olive oils sensory quality was assessed by trained panelists, according to EU Commission Regulation (Consolidated Text 1991R2568 - EN - 01.01.2015 -027.001), aiming to establish the quality grade of each olive oil. The olive oils studied were previously described by Slim and co-workers (Slim et al., 2017). According to the label information, 2 olive oils were extracted from olives from Oueslati cv, also known as El Leguim, 11 olive oils from Chétoui cv, and 26 olive oils from Sahli cv. The scope of the study was, therefore, to identify, through chemometric tools, possible chemical markers that could be used to discriminate the selected monovarietal olive oils classified as Ancient Olive Orchards (AOOs) (Slim et al., 2017).

\section{MATERIALS AND METHODS}

\section{Autochthonous Tunisian olive oil samples}

Thirty nine commercial Tunisian olive oils produced from three different autochthonous olive cultivars (cv Chétoui11 bottles, cv Sahli - 26 bottles, and cv Oueslati - 2 bottles, according to the label information) were purchased in Tunisia and kept in the original dark amber bottles to minimize the risk of quality degradation until analysis at the laboratories of the School of Agriculture - Polytechnic Institute of Bragança and Faculty of Pharmacy - University of Porto, both in Portugal, as previously described (Slim et al., 2017). Details regarding the three olive cultivars studied can be found in the literature (Grati-Kamoun et al., 2006).

\section{Chemical and sensory analysis}

All samples, before their expiration date, were analyzed according to the European Union standard methods (Consolidated Text 1991R2568 - EN - 01.01.2015 - 027.001). From each olive oil, two independent samples were collected and all the analysis were carried out in duplicate. Five quality parameters were assessed namely, the free acidity (FA, in \% oleic acid), peroxide values (PV, in $\mathrm{mEq} \mathrm{O}_{2} / \mathrm{kg}$ ) as well as the specific coefficients of extinction at $232 \mathrm{~nm}$ and $270 \mathrm{~nm}\left(K_{232}\right.$ and $K_{270}$ and $\Delta K)$. Also, olive oil samples were evaluated by 8 trained panelists following the EU Regulation (Consolidated Text 1991R2568 - EN - 01.01.2015 - 027.001) aiming to assess the intensity of fruity positive attribute (i.e. the set of olfactory sensations coming from sound, fresh ripe or unripe olives, which are perceived directly and/or through the back of the nose) as well as the presence and intensity of common negative attributes (such as fusty, musty, winey-vinegary and/or rancid). Olive oils were classified as EVOO if, simultaneously, FA $\leq 0.8 \%$ oleic acid, $\mathrm{PV} \leq 20 \mathrm{mEq} \mathrm{O}{ }_{2} / \mathrm{kg}, K_{232} \leq 2.50, K_{270} \leq 0.22, \Delta K \leq 0.01$, median intensity of sensory defects equal to 0 and median intensity of fruitiness greater than 0 . Olive oils would be classified as VOO if, at the same time, FA $\leq 2.0 \%$ oleic acid, $\mathrm{PV} \leq 20 \mathrm{mEq} \mathrm{O}_{2} / \mathrm{kg}, K_{232} \leq 2.60, K_{270} \leq 0.25, \Delta K \leq 0.01$, median intensity of sensory defect between 0 and 3.5 (in an ordinal intensity scale ranging from 0 to 10) and median intensity of fruitiness higher than 0 (in an ordinal intensity scale ranging from 0 to 7). Olive oils would be classified as LOO if at least one of the previous conditions is not fulfilled. It should be remarked, that positive olfactory and gustatory-retronasal sensory attributes were only evaluated if no organoleptic defect was perceived or if its intensity was lower than 3.5. The olive oils oxidative stabilities (OS) were also determined using a Rancimat apparatus following the standard methodology (ISO 6886:2016). The antioxidant activity was evaluated using the DPPH assay according to Kalantzakis and co-workers (Kalantzakis et al., 
2006), which together with ABTS, CUPRAC, FRAP and ORAC assays, are commonly used to assess the antioxidant capacity of different food matrices (Thaipong et al., 2006; Apak et al., 2007; Yashin et al., 2013; Giuffrè et al., 2016, 2017a,b,c); the total phenols (TP) contents were assessed as described by Capannesi and co-workers (Capannesi et al., 2010); tocopherols contents ( $\alpha-, \beta-, \gamma$ - and total) were determined by normal phase high performance liquid chromatography(HPLC) using 2-methyl-2-(4,8,12-trimethyl tridecyl) chroman-6-ol (tocol) (Matreya Inc., Pleasant Gap, PA) as the internal standard (ISO 9936:2016) and the fatty acids profiles were obtained by gas-chromatography (GC) after cold alkaline transesterification (Consolidated Text 1991R2568 - EN - 01.01.2015 - 027.001). The liquid chromatograph consisted of a Jasco integrated system (Japan) equipped with a Jasco LC-NetII/ADC data unit, a PU-1580 Intelligent Pump and a FP-920 fluorescence detector $\left(\lambda_{\text {exc }}=290 \mathrm{~nm}\right.$ and $\left.\lambda_{\mathrm{em}}=330 \mathrm{~nm}\right)$. The chromatographic separation was achieved by mean of a Supelcosil TM LC-SI column (Supelco, Bellefonte, PA) (3 $\mu \mathrm{m} ; 75 \times 3.0 \mathrm{~mm}$, operating at $23^{\circ} \mathrm{C}$. Gas chromatography was carried out with a Chrompack CP 9001 chromatograph equipped with a split-splitless injector, a FID detector, an Chrompack CP-9050 autosampler and a $50 \mathrm{~m} \times 0.25 \mathrm{~mm}$ i.d. fused silica capillary column coated with a $0.19 \mu \mathrm{m}$ film of CP-Sil 88 (Varian). Helium was used as carrier gas at an internal pressure of $110 \mathrm{kPa}$. The temperatures of the detector and injector were $250^{\circ} \mathrm{C}$ and $230^{\circ} \mathrm{C}$, respectively. The split ratio was 1:50 and the injected volume was of $1 \mu \mathrm{l}$.

\section{Statistical analysis}

One-way ANOVA was used to verify if the olive cultivar used on the production of each monovarietal olive oil (cvs Chétoui, Oueslati or Sahli) would significantly influence the chemical contents. When significant statistical differences were found, the Tukey's post-hoc multi-comparison test was further used. For this analysis the olive oil quality grade was not taken into account. Furthermore, to identify possible putative biomarkers to distinguish autochthonous Tunisian olive oils according to the olive cultivar, two multivariate approaches were applied: the unsupervised principal component analysis (PCA) and the supervised linear discriminant analysis (LDA) coupled to a meta-heuristic simulated annealing (SA) variable selection algorithm (Kirkpatrick et al., 1983; Bertsimas and Tsitsiklis, 1992; Cadima et al., 2004). Taking into account the database size, considering that only two independent monovarietal olive oil bottles were produced from Oueslati olives, the multivariate techniques were only considered for monovarietal olives from Chétoui and Sahli cvs. Moreover, for the LDA-SA procedure, the predictive performance of the established classification model was further verified using two cross-validation $(\mathrm{CV})$ variants: the LOO-CV procedure, which although being described as an over-optimistic procedure it has been also been reported as a suitable cross-validation variant (Martens and Dardenne, 1998), when small databases are available; and, the repeated $\mathrm{K}$-fold-CV procedure, aiming to minimize overfitting risks. In the last case, data was randomly split into $\mathrm{K}$ folds, being each of the folds left out in turn and the other K-1 folds used to train the model. The held out fold is used for test purposes and the quality of the predictions is assessed using the percentage of correct classifications. As previously (Slim et al., 2016; Souayah et al., 2017), in this study the K-folds were set equal to 4, enabling the random formation of internal validation subsets (for each gustatory group) with $25 \%$ of the initial data, allowing bias reduction. The procedure was repeated 10 times for putting the model under stress. The repeated K-fold-CV technique allows reducing the uncertainty of the estimates, by evaluating the predictive performance of the models established using $4 \times 10$ random sub-sets (i.e. 40 total resamples used for internal validation). To normalize the weight of each variable in the final linear classification model, variable scaling and centering procedures were evaluated. The classification performance of the LDA model was graphically evaluated by plotting the density distribution of the data for the sole discriminant function. Statistical analysis was performed using the sub-select (Bertsimas and Tsitsiklis, 1992; Cadima et al., 2012) and MASS (Venables and Ripley, 2002) packages of the open source statistical program $\mathrm{R}$ (version 2.15.1), at a $5 \%$ significance level.

\section{RESULTS AND DISCUSSION}

\section{Autochthonous Tunisian olive oils quality grade classification}

Taking into account simultaneously the quality (FA, PV, $K_{232}, K_{270}$ and $\Delta K$ values) and sensory evaluation data, the thirty-nine Tunisian olive oils under investigation were classified as follows: 2 samples were EVOO, 4 samples VOO, and 33 samples LOO (Table 1).

The high number of commercial olive oils classified as LOO ( $\sim 85 \%$ of the samples evaluated) clearly suggest that extra monitoring and controlling quality measures must be implemented to guarantee higher quality standards of the Tunisian olive oils that reach the consumer. However, it should be remarked that this lower quality classification was mainly due to the high $K_{232}$ values determined $(82 \%$ of the samples are classified as LOO based on the values of this parameter), indicative of the primary oxidation. This fact may be attributed to the high average temperatures registered in Tunisia and the little differences on climate between seasons in semi-arid geographical areas (Kotti et al., 2009) and to the storage conditions of the olive oils before being purchased. Indeed, 
Table 1: Monovarietal Tunisian olive oils details: olive cultivar, sensory analysis (fruitiness positive attribute, organoleptic defect and respective median perceived intensities), chemical parameters and mean quality parameter values (free acidity, peroxide values, $K_{232}, K_{270}$ and $\Delta K$ ). For the cases where more than one olive oil was evaluated, minimum and maximum values are given in brackets. When only one olive oil was available the standard deviation regarding the two sub-samples analyzed in duplicate is given

\begin{tabular}{|c|c|c|c|c|c|c|c|c|}
\hline \multirow{2}{*}{$\begin{array}{l}\text { Autochthonous } \\
\text { olive cultivar }\end{array}$} & \multicolumn{2}{|c|}{ Sensory analysis } & \multicolumn{5}{|c|}{ Chemical quality parameters } & \multirow{2}{*}{$\begin{array}{l}\text { Quality grade } \\
\text { classification }^{2}\end{array}$} \\
\hline & $\begin{array}{c}\text { Fruity } \\
\text { (median } \\
\text { intensity) }\end{array}$ & $\begin{array}{c}\text { Defect } \\
\text { (median intensity) }\end{array}$ & $\begin{array}{c}\text { Free Acidity } \\
(\%)\end{array}$ & $\begin{array}{c}\text { Peroxide } \\
\text { value } \\
\left(\mathrm{mEq} \mathrm{O}_{2} / \mathrm{kg}\right) \\
\end{array}$ & $K_{232}$ & $K_{270}$ & $\Delta K$ & \\
\hline \multirow[t]{3}{*}{ cv Chétoui } & - & - & - & - & - & - & - & EVOO $(n=0)$ \\
\hline & 6.0 & 0 & $1.0(0.3-1.6)$ & $6.4(5.8-7.5)$ & $2.29(1.69-2.63)$ & $0.17(0.10-0.22)$ & $0.00(0.00-0.00)$ & VOO $(n=2)$ \\
\hline & n.a. & $>3.5$ & $0.5(0.3-2.8)$ & $8.8(5.0-24.0)$ & $3.23(2.64-3.77)$ & $0.22(0.16-0.26)$ & $0.00(-0.01-0.00)$ & LOO $(n=9)$ \\
\hline \multirow[t]{3}{*}{ cv Oueslati } & - & - & - & - & - & - & - & EVOO $(n=0)$ \\
\hline & 6.0 & 0 & $0.8 \pm 0.1$ & $8.7 \pm 0.6$ & $2.03 \pm 0.05$ & $0.13 \pm 0.01$ & $0.00 \pm 0.00$ & VOO $(n=1)$ \\
\hline & n.a. & $>3.5$ & $0.6 \pm 0.1$ & $11.6 \pm 0.0$ & $2.70 \pm 0.16$ & $0.17 \pm 0.00$ & $0.00 \pm 0.00$ & LOO $(n=1)$ \\
\hline \multirow[t]{3}{*}{ cv Sahli } & 6.0 & 0 & $0.5(0.4-0.6)$ & $9.4(5.8-13.3)$ & $1.87(1.16-2.47)$ & $0.19(0.18-0.21)$ & $0.00(-0.00-0.00)$ & EVOO $(n=2)$ \\
\hline & 5.5 & $<3.5$ & $0.6 \pm 0.0$ & $10.8 \pm 5.9$ & $2.52 \pm 1.54$ & $0.17 \pm 0.01$ & $0.00 \pm 0.01$ & VOO $(n=1)$ \\
\hline & n.a. & $>3.5$ & $0.6(0.3-1.4)$ & $11.5(4.2-23.2)$ & $3.55(2.61-5.17)$ & $0.18(0.12-0.33)$ & $0.00(-0.06-0.02)$ & LOO $(n=23)$ \\
\hline
\end{tabular}

n.a.: gustatory-retronasal fruity attribute not evaluated since a defect was perceived by the trained panelists with an intensity greater than 3.5 ${ }^{1}$ Olive cultivar identification according to the label information

${ }^{2}$ Quality grade classification according EU Commission regulation (Consolidated Text 1991R2568 - EN - 01.01.2015-027.001):EVOO (simultaneously: FA $\leq 0.8 \%$ oleic acid, $\mathrm{PV} \leq 20 \mathrm{mEq} \mathrm{O} / \mathrm{kg}, K_{232} \leq 2.50, K_{270} \leq 0.22, \Delta K \leq 0.01$, median intensity of sensory defects=0 and median intensity of fruity positive attribute>0); VOO (simultaneously: FA $\leq 2.0 \%$ oleic acid, $\mathrm{PV} \leq 20 \mathrm{mEq} \mathrm{O} / \mathrm{kg}, K_{232} \leq 2.60, K_{270} \leq 0.25, \Delta K \leq 0.01,0<$ median intensity of sensory defects $\leq 3.5$ and median intensity of fruity positive attribute>0); or, LOO (for the other cases)

for the other chemical quality parameters evaluated, the majority of the olive oils analyzed did not exceed the limit legal levels: FA (no sample would be classified as LOO considering this single parameter), PV (only 3 of the samples would be classified as LOO considering this single parameter), $K_{270}$ or $\Delta K$ (only 2 samples would be classified as LOO considering each single parameter). Simultaneously, the sensory evaluation performed resulted in the perception of negative organoleptic attributes with intensities greater than 3.5 (mainly rancid, winey-vinegary and fusty) in $59 \%$ of the olive oil samples, reason why those olive oils were classified as LOO, regardless the levels of quality chemical parameters, in accordance to the EU Commission regulation (Consolidated Text 1991R2568 - EN - 01.01.2015 - 027.001). It should be also noticed that the other samples could be classified as EVOO based only on the sensory evaluation, since no organoleptic defect could be perceived by the trained panelists.

Overall, the high number of monovarietal Tunisian olive oils classified as LOO was surprising, since in the majority of works that deal with chemical characterization of monovarietal Tunisian olive oils from Chétoui, Oueslati and Sahli cvs (Dhi et al., 2004; Temine et al., 2006; Issaoui et al., 2007; Krichene et al., 2007; Haddada et al., 2008; Dabbou et al., 2009; Guerfel et al., 2009; Kotti et al., 2009; Dabbou et al., 2010; Taamalli et al., 2010; Dabbou et al., 2011; Youssef et al., 2011; Issaoui et al., 2012; Laroussi-Mezghani et al., 2015; Essid et al., 2016; Hassine et al., 2015; Fares et al., 2016; Loubiri et al., 2017; Ouni et al., 2017), these oils were always reported as EVOO or VOO, according to the legal regulations (Consolidated Text 1991R2568 - EN - 01.01.2015 - 027.001). This could be explained considering that the olive oil samples investigated in the previous research works, were obtained under controlled conditions (including olive production, olive oil processing and storage conditions). In the present study, on the contrary, aiming at evaluating the quality and composition of commercial Tunisian olive oil samples usually bought by typical consumers, samples were purchased directly from the markets.

\section{Effect of the autochthonous olive cultivar on the chemical profiles of Tunisian olive oils}

The possible effect of the olive cultivar on the chemical composition of the Tunisian olive oils, regardless their quality grade classification, was evaluated using one-way ANOVA, using the experimental data from two independent samples of each olive oil bottle (being each sample analyzed in triplicate). Concerning the fatty acid profile, only those olive oils that had a mean relative percentage in the total fat greater than $0.01 \%$ were considered for statistical analysis. The results shown in Table 2 indicated that the commercial Chétoui or Oueslati monovarietal olive oils had fatty acids contents (individual fatty acids as well as SFA, MUFA and PUFA) within the interval ranges previously reported by several other researchers (Dhi et al., 2004; Temine et al., 2006; Issaoui et al., 2007; Krichene et al., 2007; Haddada et al., 2008; Dabbou et al., 2009; Guerfel et al., 2009, Kotti et al., 2009; Dabbou et al., 2010; Taamalli et al., 2010; Dabbou et al., 2011; Youssef et al., 2011; Issaoui et al., 2012; Laroussi-Mezghani et al., 2015; Hassine et al., 2015; Essid et al., 2016; Fares et al., 2016; Gargouri et al., 2016, Hlima et al., 2017; Loubiri et al., 2017; Ouni et al., 2017), showing that fatty acids profiles are rather related to olive cultivar than olive oil quality grade. Also, broad 
Table 2: Fatty acids profile of monovarietal tunisian olive oils of autochthonous olive cultivars (cvs Chétoui, Oueslati and Sahli): comparison with literature data

\begin{tabular}{|c|c|c|c|c|c|c|c|c|}
\hline \multirow{3}{*}{$\begin{array}{l}\text { Fatty acid } \\
\text { composition } \\
\text { (relative \% in the } \\
\text { total fat) }\end{array}$} & \multicolumn{8}{|c|}{ Tunisian olive oils from autochthonous olive cultivars } \\
\hline & \multicolumn{4}{|c|}{ This work (mean values \pm standard deviation) ${ }^{1}$} & \multicolumn{3}{|c|}{ Literature data levels } & \multirow[t]{2}{*}{ References } \\
\hline & $\begin{array}{c}\text { cv } \\
\text { Chétoui }^{2}\end{array}$ & $\begin{array}{c}\text { cv } \\
\text { Oueslati }^{3}\end{array}$ & $\begin{array}{c}\text { cv } \\
\text { Sahli }^{4}\end{array}$ & $P$-value ${ }^{5}$ & $\begin{array}{l}\text { cv } \\
\text { Chétoui }\end{array}$ & $\begin{array}{c}\text { cv } \\
\text { Oueslati }\end{array}$ & $\begin{array}{c}\text { cv } \\
\text { Sahli }\end{array}$ & \\
\hline C14:0 (myristic acid) & $0.02 \pm 0.01^{a}$ & $0.02 \pm 0.00^{\mathrm{a}, \mathrm{b}}$ & $0.01 \pm 0.00^{b}$ & 0.0090 & n.a. & n.a. & n.a. & ---- \\
\hline C16:0 (palmitic acid) & $12.49 \pm 1.88^{b}$ & $12.64 \pm 1.13^{b}$ & $16.77 \pm 2.64^{a}$ & $<0.0001$ & $8.08-14.18$ & $9.45-19.51$ & $15.67-17.39$ & (A) \\
\hline C17:0 (margaric acid) & $0.07 \pm 0.03^{a}$ & $0.04 \pm 0.00^{\mathrm{b}}$ & $0.05 \pm 0.01^{b}$ & 0.0015 & $0.04-0.06$ & $0.02-0.05$ & 0.04 & (B) \\
\hline C18:0 (stearic acid) & $2.89 \pm 0.34^{a}$ & $2.34 \pm 0.15^{\mathrm{b}}$ & $2.40 \pm 0.30^{b}$ & $<0.0001$ & $0.20-3.70$ & $0.20-3.55$ & $2.62-2.82$ & (C) \\
\hline C20:0 (arachidic acid) & $0.47 \pm 0.03^{a}$ & $0.43 \pm 0.01^{\mathrm{a}, \mathrm{b}}$ & $0.44 \pm 0.03^{b}$ & 0.0008 & $0.27-0.67$ & $0.32-0.48$ & $0.48-0.62$ & (D) \\
\hline C22:0 (behenic acid) & $0.12 \pm 0.01^{a}$ & $0.13 \pm 0.00^{a}$ & $0.13 \pm 0.01^{a}$ & 0.0471 & $0.11-0.47$ & $0.13-0.15$ & $0.22-0.29$ & (E) \\
\hline $\begin{array}{l}\text { C24:0 } \\
\text { (lignoceric acid) }\end{array}$ & $0.05 \pm 0.01^{b}$ & $0.06 \pm 0.01^{a, b}$ & $0.06 \pm 0.01^{a}$ & 0.0040 & $0.04-0.12$ & $0.06-0.08$ & $0.13-0.18$ & $(F)$ \\
\hline$\Sigma$ SFA & $16.13 \pm 1.57^{b}$ & $15.70 \pm 1.00^{b}$ & $19.88 \pm 2.37^{a}$ & $<0.0001$ & $11.90-16.23$ & $14.25-15.95$ & ---- & (G) \\
\hline $\begin{array}{l}\text { C16:1 } \\
\text { (palmitoleic acid) }\end{array}$ & $0.75 \pm 0.58^{b}$ & $0.98 \pm 0.27^{b}$ & $2.10 \pm 0.84^{a}$ & $<0.0001$ & $0.07-0.70$ & $0.20-3.45$ & $1.54-1.92$ & $(\mathrm{H})$ \\
\hline $\begin{array}{l}\text { C17:1 } \\
\text { (heptadecenoic acid) }\end{array}$ & $0.08 \pm 0.05$ & $0.07 \pm 0.01$ & $0.08 \pm 0.01$ & 0.4768 & $0.03-0.06$ & $0.05-0.09$ & 0.07 & (I) \\
\hline C18:1 (oleic acid) & $66.14 \pm 2.37^{a}$ & $69.79 \pm 1.35^{\mathrm{a}}$ & $60.66 \pm 3.80^{b}$ & $<0.0001$ & $54.80-74.33$ & $56.10-75.82$ & $63.05-65.27$ & $(\mathrm{~J})$ \\
\hline $\begin{array}{l}\text { C20:1 } \\
\text { (eicosenoic acid) }\end{array}$ & $0.38 \pm 0.06^{a}$ & $0.35 \pm 0.01^{a, b}$ & $0.27 \pm 0.07^{b}$ & $<0.0001$ & $0.16-0.44$ & $0.28-1.12$ & n.a. & $(\mathrm{K})$ \\
\hline$\Sigma$ MUFA & $67.36 \pm 2.06^{b}$ & $\begin{array}{c}71.185 \pm \\
1.07^{\mathrm{a}}\end{array}$ & $63.11 \pm 3.08^{c}$ & $<0.0001$ & $55.20-74.45$ & 71.13-72.29 & ---- & (L) \\
\hline C18:2 (linoleic acid) & $15.46 \pm 1.68^{a}$ & $12.35 \pm 0.13^{b}$ & $16.16 \pm 1.40^{a}$ & $<0.0001$ & $10.84-27.80$ & $8.99-23.10$ & $12.75-13.18$ & (M) \\
\hline $\begin{array}{l}\text { C18:3n3 } \\
\text { (linolenic acid) }\end{array}$ & $0.73 \pm 0.09$ & $0.70 \pm 0.07$ & $0.74 \pm 0.05$ & 0.3364 & $0.55-0.90$ & $0.53-1.60$ & $0.74-0.86$ & $(\mathrm{~N})$ \\
\hline$\Sigma$ PUFA & $16.19 \pm 1.74^{a}$ & $13.05 \pm 0.13^{b}$ & $16.90 \pm 1.41^{a}$ & $<0.0001$ & $12.56-28.60$ & $12.83-13.21$ & ---- & (O) \\
\hline Trans oleic acid & $0.03 \pm 0.01$ & $0.03 \pm 0.01$ & $0.02 \pm 0.01$ & 0.2174 & n.a. & n.a. & n.a. & ---- \\
\hline $\begin{array}{l}\text { Trans } \\
\text { Linoleic+linolenicacids }\end{array}$ & $0.04 \pm 0.01$ & $0.03 \pm 0.01$ & $0.04 \pm 0.01$ & 0.3660 & n.a. & n.a. & n.a. & ---- \\
\hline ¿trans & $0.07 \pm 0.01$ & $0.06 \pm 0.02$ & $0.06 \pm 0.01$ & 0.2925 & --- & --- & --- & --- \\
\hline
\end{tabular}

n.a.: not available

${ }^{1}$ Different lowercase letters within the same line (i.e., for the same parameter) means a significant statistical difference at a $5 \%$ significance level, based on the Tukey's test

${ }^{2}$ Two samples from each of the eleven olive oil bottles analyzed in triplicate; 3Two samples from each of the two olive oil bottles analyzed in triplicate ${ }^{4}$ Two samples from each of the twenty-six olive oil bottles analyzed in triplicate; 5P-value for the one-way ANOVA

(A)Dhi et al. (2004); Temine et al. (2006); Issaoui et al. (2007); Krichene et al. (2007); Haddada et al. (2008); Dabbou et al. (2009); Guerfel et al. (2009); Kotti et al. (2009); Dabbou et al. (2010); Dabbou et al. (2011); Youssef et al. (2011); Issaoui et al. (2012); Laroussi-Mezghani et al. (2015); Hassine et al. (2015); Fares et al. (2016); Laroussi-Mezghani et al. (2016); Ouni et al. (2016); Hlima et al. (2017)

(B)Issaoui et al. (2007); Dabbou et al. (2009, 2010, 2011); Laroussi-Mezghani et al. (2015); Hassine et al. (2015); Fares et al. (2016); Laroussi-Mezghani et al. (2016); Hlima et al. (2017)

(C)Dhi et al. (2004); Temine et al. (2006); Issaoui et al. (2007); Krichene et al. (2007); Dabbou et al. (2009); Guerfel et al. (2009); Dabbou et al. (2010); Taamalli et al. (2010); Dabbou et al. (2011); Youssef et al. (2011); Issaoui et al. (2012); Laroussi-Mezghani et al. (2015); Hassine et al. (2015); Fares et al. (2016); Laroussi-Mezghani et al. (2016); Hlima et al. (2017)

(D)Temine et al. (2006); Issaoui et al. (2007); Krichene et al. (2007); Dabbou et al. (2009, 2010); Taamalli et al. (2010); Dabbou et al. (2011); Youssef et al. (2011); Laroussi-Mezghani et al. (2015); Hassine et al. (2015); Fares et al. (2016); Laroussi-Mezghani et al. (2016); Hlima et al. (2017)

(E)Issaoui et al. (2007); Dabbou et al. (2009, 2010, 2011); Laroussi-Mezghani et al. (2015); Laroussi-Mezghani et al. (2016)

(F)Issaoui et al. (2007); Laroussi-Mezghani et al. (2015, 2016)

(G)Krichene et al. (2007); Guerfel et al. (2009); Youssef et al. (2011); Issaoui et al. (2012); Hlima et al. (2017)

(H)Dhi et al. (2004); Temine et al. (2006); Issaoui et al. (2007); Krichene et al. (2007); Haddada et al. (2008); Dabbou et al. (2009); Guerfel et al. (2009); Kotti et al. (2009); Dabbou et al. (2010); Taamalli et al. (2010); Dabbou et al. (2011); Youssef et al. (2011); Issaoui et al. (2012); Laroussi-Mezghani et al. (2015); Hassine et al. (2015); Fares et al. (2016); Laroussi-Mezghani et al. (2016); Ouni et al. (2016); Hlima et al. (2017)

(I)Issaoui et al. (2007); Dabbou et al. (2009, 2010, 2011); Laroussi-Mezghani et al. (2015); Hassine et al. (2015); Fares et al. (2016); Laroussi-Mezghani et al. (2016); Hlima et al. (2017)

(J)Dhi et al. (2004); Temine et al. (2006); Issaoui et al. (2007); Krichene et al. (2007); Haddada et al. (2008); Dabbou et al. (2009); Guerfel et al. (2009); Kotti et al. (2009); Dabbou et al. (2010); Taamalli et al. (2010); Dabbou et al. (2011); Youssef et al. (2011); Issaoui et al. (2012); Hassine et al. (2015); Laroussi-Mezghani et al. (2015); Fares et al. (2016); Laroussi-Mezghani et al. (2016); Ouni et al. (2016); Hlima et al. (2017)

(K)Dabbou et al. (2009, 2010, 2011); Hassine et al. (2015); Laroussi-Mezghani et al. (2015); Fares et al. (2016); Laroussi-Mezghani et al. (2016); Hlima et al. (2017)

(L)Krichene et al. (2007); Guerfel et al. (2009); Taamalli et al. (2010); Youssef et al. (2011); Issaoui et al. (2012); Hlima et al. (2017)

(M)Dhi et al. (2004); Temine et al. (2006); Issaoui et al. (2007); Krichene et al. (2007); Haddada et al. (2008); Dabbou et al. (2009); Guerfel et al. (2009); Kotti et al. (2009); Dabbou et al. (2010); Taamalli et al. (2010); Dabbou et al. (2011); Youssef et al. (2011); Issaoui et al. (2012); Hassine et al. (2015); Laroussi-Mezghani et al. (2015); Fares et al. (2016); Laroussi-Mezghani et al. (2016); Ouni et al. (2016); Hlima et al. (2017)

(N)Dhi et al. (2004); Temine et al. (2006); Issaoui et al. (2007); Krichene et al. (2007); Haddada et al. (2008); Dabbou et al. (2009); Guerfel et al. (2009); Kotti et al. (2009); Dabbou et al. (2010); Taamalli et al. (2010); Dabbou et al. (2011); Youssef et al. (2011); Issaoui et al. (2012); Laroussi-Mezghani et al. (2015); Fares et al. (2016); Laroussi-Mezghani et al. (2016); Ouni et al. (2016); Hlima et al. (2017)

(O)Krichene et al. (2007); Guerfel et al. (2009); Taamalli et al. (2010); Youssef et al. (2011); Issaoui et al. (2012); Hlima et al. (2017) 
contents interval ranges have been reported for those two monovarietal Tunisian olive oils, showing that the geographical origin and related agricultural practices may also influence the fatty acids profiles. The fatty acids profiles determined for Sahli single-cultivar olive oils showed some differences compared to the values previously reported (Issaoui et al., 2007) containing lower mean total MUFA level (higher mean contents of C16:1 and C17:1 and lower mean content of C18:1) and higher mean total PUFA level (higher mean content of C18:2). These differences could be partially attributed to the fact that the Sahli monovarietal olive oils reported in the literature (Issaoui et al., 2007) were produced from olives cultivated under the same edaphic-climatic conditions and grown in same geographic region (National Collection "Boughrara" in Sfax south of Tunisia), which may lead to narrow interval ranges. On the contrary, Sahli olive oils studied in the present work were commercially obtained and were produced in different Tunisian areas, under unknown production and storage conditions. Finally, it should be remarked that for Chétoui and Oueslati olive oils, some of the literature values reported for oleic acid content are near or lower the legal limit of $55 \%$. On the contrary, all the Tunisian olive oils evaluated in the present study had mean oleic acid contents greater than the minimum legal level.

Moreover, in all the analyzed olive oils, it was possible to detect tocopherols and the results obtained were in agreement with those reported in the literature. Table 3 summarizes the mean contents ( \pm standard deviations) of the chemical parameters and of the tocopherols contents evaluated for each monovarietal olive oil, as well as the cases where statistical significant differences were found according to the type of autochthonous olive cultivar used for olive oil production (based on the one-way ANOVA and Tukey's test results). For the above-mentioned parameters, the range levels available in the literature referring to VOO and EVOO of cvs Chétoui, Oueslati and Sahli are also given. It should be remarked that, only one work related to the genetic variety was found (Issaoui et al., 2007). Once again, the values reported showed a high variability, which was expected since it is known that the chemical composition of olive oils may be greatly influenced by climatic factors and/or geographical origin (Kotti et al., 2009).

Briefly, among the studied commercial monovarietal Tunisian olive oils under investigation, olive oils from Sahli olive cultivar had the lowest total phenolic content $(157 \pm 48 \mathrm{mg} / \mathrm{kg})$, oxidative stability $(6.5 \pm 2.1 \mathrm{~h}), \mathrm{DPPH}$ scavenging activity $(68 \% \pm 14)$ and monounsaturated fatty acids content $(63.1 \% \pm 3.1)$. On the other hand, those olive oils possessed the highest saturated and polyunsaturated fatty acids contents $(19.9 \% \pm 2.4$ and $16.9 \% \pm 1.4)$ as well as total tocopherols levels $(222 \pm 49 \mathrm{mg} / \mathrm{kg})$. The greater PUFA content determined for Sahli olive oils may explain the lower oxidative stability found. These findings could be further used to identify possible chemical markers for traceability studies.

Table 3: Chemical characteristics and tocopherols contents of monovarietal Tunisian olive oils of autochthonous olive cultivars (cvs Chétoui, Oueslati and Sahli): comparison with literature data

\begin{tabular}{|c|c|c|c|c|c|c|c|c|}
\hline \multirow[t]{3}{*}{ Parameter } & \multicolumn{8}{|c|}{ Tunisian olive oils from autochthonous olive cultivars } \\
\hline & \multicolumn{4}{|c|}{ This work (mean values \pm standard deviation) ${ }^{1}$} & \multicolumn{3}{|c|}{ Literature data levels } & \multirow[t]{2}{*}{ References } \\
\hline & cv Chétoui ${ }^{2}$ & cv Oueslati ${ }^{3}$ & cv Sahli ${ }^{4}$ & $P$-value ${ }^{5}$ & cv Chétoui & cv Oueslati & cv Sahli & \\
\hline \multicolumn{9}{|l|}{ Chemical parameters } \\
\hline Total phenols $(\mathrm{mg} / \mathrm{kg})$ & $190 \pm 48$ & $157 \pm 8^{\mathrm{a}, \mathrm{b}}$ & $157 \pm 48^{b}$ & 0.0346 & $65-1004$ & 84-396 & 97 & (A) \\
\hline Oxidative stability (h) & $9.2 \pm 2.7^{\mathrm{a}}$ & $9.0 \pm 0.4^{a, b}$ & $6.5 \pm 2.1^{\mathrm{b}}$ & $<0.0001$ & 4.3-77.3 & 4.7-103.6 & n.a. & (B) \\
\hline $\begin{array}{l}\text { DPPH scavenging } \\
\text { activity }(\%)\end{array}$ & $81.0 \pm 14.3^{a}$ & $63.3 \pm 1.4^{a, b}$ & $\begin{array}{c}68.4 \pm \\
14.2^{\mathrm{b}}\end{array}$ & 0.0016 & 97 & $42-87$ & n.a. & (C) \\
\hline \multicolumn{9}{|c|}{ Tocopherols content (mg/kg olive oil) } \\
\hline$\alpha$-tocopherol & $234 \pm 63^{a}$ & $147 \pm 18^{b}$ & $216 \pm 48^{a}$ & 0.0107 & $271-557$ & $136-480$ & n.a. & (D) \\
\hline$\beta$-tocopherol & $2.2 \pm 0.72^{\mathrm{b}}$ & $3.3 \pm 0.38^{a}$ & $1.7 \pm 0.41^{c}$ & $<0.0001$ & $5-26$ & 5-25 & n.a. & $(E)$ \\
\hline$\gamma$-tocopherol & $5.5 \pm 1.05^{a}$ & $1.8 \pm 0.62^{c}$ & $3.9 \pm 1.27^{b}$ & $<0.0001$ & $6-33$ & $5-26$ & n.a. & $(F)$ \\
\hline $\begin{array}{l}\text { Total tocopherol } \\
\text { content }\end{array}$ & $242 \pm 64^{a}$ & $152 \pm 18^{b}$ & $222 \pm 49^{a}$ & 0.0089 & 207.21-616 & $146-338$ & $195-227$ & (G) \\
\hline
\end{tabular}

n.a.: not available

${ }^{1}$ Different lowercase letters within the same line (i.e., for the same parameter) means a significant statistical difference at a $5 \%$ significance level, based on the Tukey's test

${ }^{2}$ Two samples from each of the eleven olive oil bottles analyzed in triplicate; ${ }^{3}$ Two samples from each of the two olive oil bottles analyzed in triplicate ${ }^{4}$ Two samples from each of the twenty-six olive oil bottles analyzed in triplicate; ${ }^{5} P$-value for the one-way ANOVA

(A) Temine et al. (2006); Issaoui et al. (2007); Krichene et al. (2007); Dabbou et al. (2009); Guerfel et al. (2009); Dabbou et al. (2010, 2011); Issaoui

et al. (2012); Hassine et al. (2015); Gargouri et al. (2016); Laroussi-Mezghani et al. (2016); Ouni et al. (2016); Loubiri et al. (2017)

(B) Temine et al. (2006); Guerfel et al. (2009); Taamalli et al. (2010); Youssef et al. (2011); Issaoui et al. (2012); Hassine et al. (2015); Hlima et al. (2017)

(C) Dabbou et al. (2009, 2010); Taamalli et al. (2010); Dabbou et al. (2011)

(D) Temine et al. (2006); Haddada et al. (2008); Dabbou et al. (2009, 2010, 2011); Hassine et al. (2015); Fares et al. (2016); Essid et al. (2016);

Laroussi-Mezghani et al. (2016)

(E) Temine et al. (2006); Hassine et al. (2015); Laroussi-Mezghani et al. (2016)

(F) Temine et al. (2006); Hassine et al. (2015); Laroussi-Mezghani et al. (2016)

(G) Temine et al. (2006); Issaoui et al. (2007); Laroussi-Mezghani et al. (2016) 
In detail, regarding the chemical parameters (Tables 2-3) assessed in this study for the Tunisian olive oils, it can be concluded that:

(i) A statistical significant effect $(P$-value $<0.05)$ of the cultivar on the total phenol mean content, oxidative stability and DPPH scavenging activity was found, being their levels different for Chétoui and Sahli olive oils, and similar for Chétoui and Oueslati cvs and for cvs Oueslati and Sahli. In general, monovarietal olive oils from Chétoui cv had the highest total phenolic content, oxidative stability and DPPH scavenging activity; monovarietal olive oils from Sahli cv had, instead, the lowest levels.

(ii) Overall, the fatty acids profile of Chétoui olive oils is statistically different from the fatty acids profile of Sahli olive oils, having the latter significantly ( $P$-value $<0.05$ ) higher contents of SFA and PUFA and lower levels of MUFA. On the other hand, no statistical significant differences were found between the fatty acids mean contents of olive oils from Chétoui and Oueslati cvs and from Oueslati and Sahli cvs. For all the olive oils assessed, the mean FA levels, and those of trans oleic acid, total trans linoleic and linolenic acids found comply the legal limits established by the EU Commission regulation.

(iii) No statistical differences $(P$-value $>0.05)$ were found between the total tocopherol mean contents determined in the olive oils, independently of the olive cultivar, although for the individual tocopherols a significant statistical effect $(P$-value $<0.05)$ of the olive cultivar was observed. Olive oils from cv Chétoui and cv Sahli showed the highest $\alpha$-, $\beta$ - and total tocopherols mean contents; olive oils from Oueslati cr showed, instead, the highest $\gamma$-tocopherol mean content.

Moreover, a comparison between the overall chemical fingerprints of the olive oils analyzed (Tables 2-3) and those reported by other researchers, pointed out the following points:

(i) The monovarietal olive oils evaluated in this work had lower total phenols contents and higher oxidative stability compared to those reported in the literature for the same autochthonous Tunisian olive oils, with the exception of cr Sahli.

(ii) The mean fatty acids contents determined for each monovarietal olive oil are within the literature range levels and comply with the legal limits established by the EU Regulation for EVOO or VOO, although the majority of the olive oils studied are classified as LOO due to chemical and sensorial characterization.

(iii) The mean tocopherols contents (total and individuals) determined for each monovarietal olive oil are lower than the literature levels. However, these low levels are consistent with the high $K_{232}$ values found for the majority of analyzed olive oils, which is indicative of the primary oxidation. It should be noted that the data in the literature vary considerable as they deal with olive oils of different geographical origins (i.e. different edaphoclimatic conditions) or with different olives maturation indexes (Haddada et al., 2008; Kotti et al., 2009).

\section{Discrimination of Tunisian olive oils according to the autochthonous olive cultivar}

The possibility of differentiating monovarietal Tunisian olive oils by their genetic variety using chemical fingerprints data (total phenols content, oxidative stability, DPPH scavenging activity, fatty acids profiles and tocopherols contents) was evaluated using unsupervised and supervised multivariate statistical techniques, PCA and LDA, which was carried out for the first time for Sahli monovarietal olive oils. At first, a PCA was carried out showing that all the chemical parameters evaluated contained representative information that allowed a natural split of the majority of the commercial monovarietal olive oils according to the olive cultivar (Fig. 1), regardless their quality classification grade (VOO or LOO) and geographical origin. Twenty-one principal components (PCs) could be established (based on the chemical data of the 24 parameters assessed), and the first 7 PCs accounted for $92 \%$ of the data variance. As can be visualized in Fig. 1 , the $1^{\text {st }}, 2^{\text {nd }}$ and $3^{\text {rd }} P C s$ (which accounted for $39.5 \%, 15.2 \%$ and $12.0 \%$ of the data variability, respectively) allowed to partially distinguish single-cultivar olive oils from Sahli cv (mostly located on the negative region of the $1^{\text {st }} \mathrm{PC}$ ) from those from Chétoui $\mathrm{cv}$ (located on the positive region of the $1^{\text {st }} \mathrm{PC}$ ). Although, some misclassification could be expected since it was not possible to form two distinct unsupervised groups. Other authors have previously showed that PCA could be used to partially differentiate Tunisian olive oils according to olive cultivar (e.g. cvs Chemlali, Chétoui, Oueslati and Zalmati (Abdallah et al., 2016); cvs Chemchali, Chemlali, Chétoui, El Hor and Jarboui and Oueslati (Guerfel et al., 2009); cvs Oueslati, Chétoui, Chemlali, Chemchali, Zalmati and Zarrazi (Laroussi-Mezghani et al., 2015); cvs Chemchali, Chemlali, Chétoui, Oueslati, Sayali, Zalmati and Zarrazi (Laroussi-Mezghani et al., 2016)), based on their chemical compositions (fatty acids, squalene, tocopherols, pigments, chlorophyll and carotenoid compounds and/or phenolic compounds).

In order to reduce the number of independent chemical parameters with discrimination capability and to establish possible putative biomarkers for the two types of monovarietal olive oils, a LDA-SA approach was used. The successful use of other linear and non-linear supervised multivariate statistical techniques has been described in the literature with similar objective (LDA coupled with 


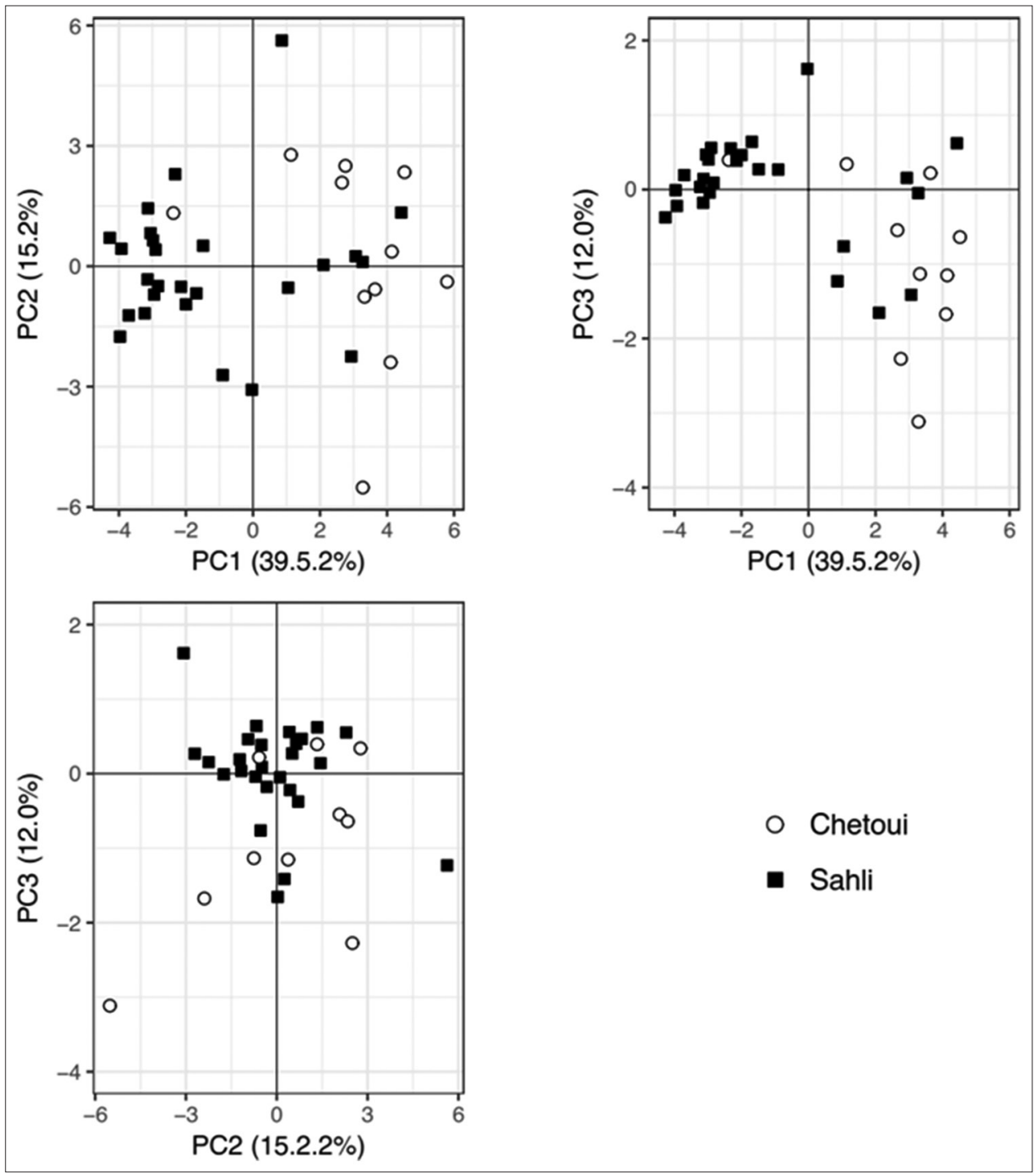

Fig 1. Monovarietal olive oils differentiation (2D PCA plot for the $1^{\text {st }}, 2^{\text {nd }}$ and $3^{\text {rd }} \mathrm{PCs}$ ) according to the Tunisian autochthonous olive cultivar, based on the data of 25 chemical parameters: total phenols content, oxidative stability, DPPH scavenging activity, fatty acids profile and tocopherols contents.

the stepwise algorithm (Taamalli et al., 2010); partial least square-discriminant analysis (PLS-DA) (Laroussi-Mezghani et al., 2016), soft independent modeling of class analogy classification (SIMCA) (Laroussi-Mezghani et al., 2015)). In the present work, the use of the meta-heuristic SA variable selection algorithm (Kirpatrick et al., 1983; Bertsimas and Tsitsiklis, 1992; Cadima et al., 2004) allowed identifying the best subsets of independent predictors (i.e., subsets comprising from 2 to 24 selected over the 25 chemical parameters assessed and described in Tables 2-3, with the exception of the trans fatty acids, which are not related with olive cultivar but with inadequate production processes) that maximized the correct classification rate of the LDA model for the original grouped data (correlation). For each LDA-DA model established the predictive potential was assessed using the LOO-CV procedures, being selected the classification model that allowed achieving the maximum correct classification percentage with the minimum number of chemical parameters. The results showed that the best LDA-SA model (with one discriminant function that explained $100 \%$ of the original data variability) was based on the chemical information of 12 independent parameters (i.e., TP, OS, C17:0, C18:0, C22:0, C24:0, C16:1, C17:1, C20:1, C22:1, C18:2 and $\gamma$-tocopherol). The selection of these chemical parameters could be attributed to the fact that the majority of them showed statistical significant differences between the two olive cultivars. The established linear classification model allowed $97.3 \%$ correct classification of the original data (one sample misclassified), i.e., of the Tunisian monovarietal olive oils according to the two autochthonous olive cultivars, regardless their quality level or geographical origin (Fig. 2) and $91.9 \%$ of predictive correct classification for the LOO-CV (three samples misclassified; one from cv Chétoui and two from cv Sahli). 
Fig. 2 shows that monovarietal olive oils of Chétoui cultivar are located in the negative region being mainly related to five fatty acids (discrimination potential: C17:0 > C24:0 $>$ C20:1 > C18:0 and C16:1), whilst, monovarietal olive oils from Sahli cv are placed on the positive region of the frequency distribution plot due to the contribution of fatty acids (discrimination potential: C22:0 >C17:1 >C22:1). Thus, among the 25 chemical parameters quantified, the discrimination results pointed out that fatty acids, mainly SFAs and MUFAs, could contribute as potential markers for assessing the genetic variety of monovarietal Tunisian olive oils. Previously, Abdallah and co-workers (Abdallah et al.2016) reported an LDA model based on the data from three fatty acids (C18:1, C16:1 and C14:0, selected by a stepwise technique), determined by DIMS, where it was possible to correctly classify EVOOs according to their genetic variety (Chemchali, Chemlali, Dhokar, Fouji, Jemri, Zalmati or Zarrazi). Recently, Laroussi-Mezghani and co-workers (Laroussi-Mezghani et al.,2015, 2016) also demonstrated the potential capability of using fatty acids compositions and other minor chemical compounds (e.g. squalene, total phenols and tocopherols) to correctly predict the genetic variety (Chemlali, Chétoui or Oueslati) of EVOO using SIMCA or PLS-DA tools (correct classification rates varying from $95 \%$ to $100 \%$ ).

The predictive capability of the LDA-SA classification model developed in this work based on the 12 chemical parameters was further assessed by applying the $K$-fold-CV procedure (4 folds $\times 10$ repetitions). For this $\mathrm{CV}$ variant, less prone to overfitting issues, the established classification model allowed obtaining a mean sensitivity of $90 \% \pm 8$ (varying from $78 \%$ to $100 \%$ for the 40 runs carried out

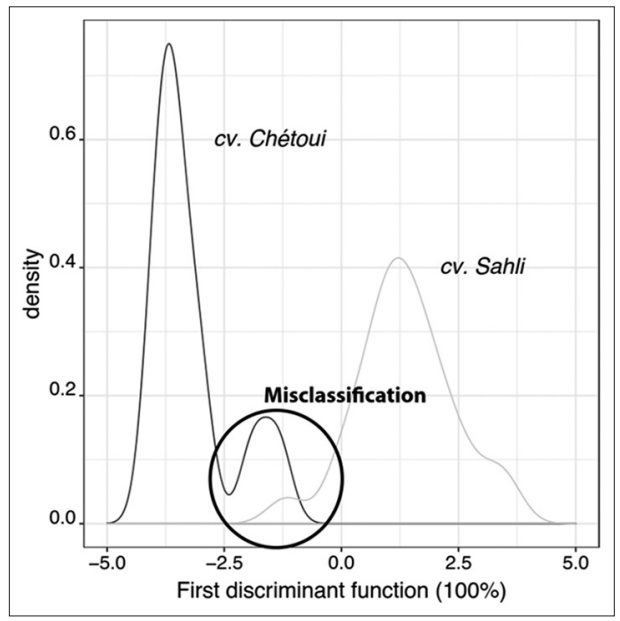

Fig 2. Density distribution (one-dimension plot) of the data for the discriminant function of the LDA-SA classification model based on 12 chemical parameters (total phenols, oxidative stability, C17:0, C18:0, C22:0, C24:0, C16:1, C17:1, C20:1, C22:1, C18:2 and $\gamma$-tocopherol) determined during the analysis of Tunisian monovarietal olive oils produced from two autochthonous cultivars (cv Chétoui and cv Sahli). during the repeated $K$-fold-CV procedure). The potential of the chemical parameters, namely the above-mentioned fatty acids (C16:1, C17:0, C17:1, C18:0, C20:1, C22:0, C22:1 and C24:0) to classify monovarietal Tunisian olive oils according to their autochthonous olive cultivar was confirmed (regardless the chemical quality level) pointing out their possible use as putative traceability chemical markers for these two Tunisian autochthonous olive cultivars.

\section{CONCLUSIONS}

In this preliminary work, it was shown that commercial Tunisian monovarietal olive oils, produced from autochthonous olive cultivars (cvs Chétoui, Oueslati and Sahli) could not be classified as extra-virgin or virgin olive oils (even if they meet many of the legal quality requirements established by the EU Commission regulations). This classification is explained by the initial high degree of oxidation, inferred due to the high values of $K_{232}$ extinction coefficient; as well as uncontrolled storage conditions that could also contribute for some organoleptic defects perceived (mainly, rancid, winey-vinegary and fusty). Overall, the Tunisian olive oils evaluated herein showed low free acidity and peroxide values, being their fatty acids levels in accordance with the legal requirements, including the values of the trans oleic and linoleic+linolenic acids. Furthermore, the levels found were in agreement with those previously reported in the literature, mainly for Chétoui or Oueslati olive oils. Also, the work contributed to a deeper chemical characterization of Sahli olive oils, a less studied Tunisian single-cultivar olive oil type, being some (bio) chemical contents significantly different from the other commercial Tunisian monovarietal olive oils studied. Finally, three minor fatty acids (heptadecenoic, behenic and erucic acids) were established as potential chemical makers for authenticity of Sahli monovarietal olive oils.

\section{ACKNOWLEDGMENTS}

This work was financially supported by Project POCI-010145-FEDER-006984 - Associate Laboratory LSRE-LCM, Project UID/QUI/00616/2013 - CQ-VR, and strategic project PEst-OE/AGR/UI0690/2014 - CIMO all funded by FEDER - Fundo Europeu de Desenvolvimento Regional through COMPETE2020 - Programa Operacional Competitividade e Internacionalização (POCI) - and by national funds through FCT - Fundação para a Ciência e a Tecnologia, Portugal. Strategic funding of UID/BIO/04469/2013 unit is also acknowledged. Nuno Rodrigues thanks FCT, POPH-QREN and FSE for the Ph.D. Grant (SFRH/BD/104038/2014). Souheib Oueslati is grateful for the support of the Tunisian Ministry of Agriculture. 


\section{Authors' Contributions}

Souihli Slim: provided the olive oil samples and carried out the quality chemical analysis; Nuno Rodrigues: supervised the chemical experiments and the related calculations; Ana C.A. Veloso: provided ideas and wrote the document; Luís G. Dias: provided ideas, carried out the statistical analysis and revised the written document; Rebeca Cruz: carried out the chromatographic analysis; Susana Casal: provided the materials and supervised the chromatographic analysis and revised the written document; Souheib Oueslati: provided the olive oil samples, contributed to the experimental setup and revised the written document; José A. Pereira: provided the materials and ideas for the study and revised the written document; António M. Peres: designed the experiments, carried out the statistical analysis and wrote the document.

\section{REFERENCES}

Abdallah, M., M. Vergara-Barberán, M. J. Lerma-García, J. M. Herrero-Martínez, E. F. Simó-Alfonso and M. Guerfel. 2016a. Classification of Tunisian extra virgin olive oils according to their genetic variety and maturity index using fatty acid profiles established by direct infusion mass spectrometry. Eur. J. Lipid Sci. Technol. 118: 735-743.

Abdallah, M., M. Vergara-Barberán, M. J. Lerma-García, J. M. Herrero-Martínez, E. F. Simó-Alfonso and M. Guerfel. 2016b. Cultivar discrimination and prediction of mixtures of Tunisian extra virgin olive oils by FTIR. Eur. J. Lipid Sci. Technol. 118: 1236-1242.

Apak, R., K. Güçlü, B. Demirata, M. Özyürek, S. E. Çelik, B. Bektaşoğlu, K. I. Berker and D. Özyurt. 2007. Comparative evaluation of various total antioxidant capacity assays applied to phenolic compounds with the CUPRAC assay. Molecules. 12: 1496-1547.

Baccouri, B., W. Zarrouk, O. Baccouri, M. Guerfel, I. Nouairi, D. Krichene, D. Daoud and M. Zarrouk. 2008. Composition, quality and oxidative stability of virgin olive oils from some selected wild olives (Olea europaea L. subsp. Oleaster). Grasas Aceites. 59: 346-351.

Bazakos, C., E. Khanfir, M. Aoun, T. Spano, Z. El Zein, L. Chalak, M. El Riachy, G. Abou-Sleymane, S. B. Ali, N. G. Kammoun and P. Kalaitzis. 2016. The potential of SNP-based PCR-RFLP capillary electrophoresis analysis to authenticate and detect admixtures of Mediterranean olive oils. Electrophoresis. 37: 1881-1890.

Bertsimas, D. and J. Tsitsiklis. 1992. Simulated annealing. Stat. Sci. 8: 10-15.

Cadima, J., J. O. Cerdeira and M. Minhoto. 2004. Computational aspects of algorithms for variable selection in the context of principal components. Comput. Stat. Data Anal. 47: 225-236.

Cadima, J., J. O. Cerdeira, P. D. Silva and M. Minhoto. 2012. The Subselect R Package. Available from: http://www.cran.rproject. org/web/packages/subselect/vignettes/subselect.pdf. [Last accessed on 2016 Feb 15].

Capannesi, C., I. Palchetti, M. Mascini and A. Parenti. 2000. Electrochemical sensor and biosensor for polyphenols detection in olive oils. Food Chem. 71: 553-562.

Consolidated Text 1991R2568 - EN - 01.01.2015 - 027.001. 2015. Characteristics of olive oil.1991R2568-EN-01.01.2015-
027.001. Annexes II, III, IX, X-B, XVI.

Dabbou, S., F. Brahmi, A. Taamali, M. Issaoui, Y. Ouni, M. Braham, M. Zarrouk and M. Hammami. 2010. Extra virgin olive oil components and oxidative stability from olives grown in Tunisia. J. Am. Oil Chem. Soc. 87: 1199-1209.

Dabbou, S., F. Brahmi, S. Dabbou, M. Issaoui, S. Sifi and M. Hammami. 2011. Antioxidant capacity of Tunisian virgin olive oils from different olive cultivars. Afr. J. Food Sci. Technol. 2: 92-97.

Dabbou, S., M. Issaoui, S. Esposto, S. Sifi, A. Taticchi, M. Servili, G. F. Montedoro and M. Hammami. 2009. Cultivar and growing area effects on minor compounds of olive oil from autochthonous and European introduced cultivars in Tunisia. J. Sci. Food Agric. 89: 1314-1325.

Dabbou, S., S. Dabbou, H. Chehab, A. Taticchi, M. Servili and M. Hammami. 2015. Content of fatty acids and phenolics in coratina olive oil from Tunisia: Influence of irrigation and ripening. Chem. Biodivers. 12: 397-406.

Dhi, W. W., I. Hamrouni, S. Ayachi, T. Chahed, M. Saïdini and B. Marzouk. 2004. Biochemical characterization of some Tunisian olive oils. J. Food Lipids. 11: 287-296.

Essid, F., S. Sifi, G. Beltrán, S. Sánchez and A. Raïes. 2016. Sensory and volatile profiles of monovarietal north Tunisian extra virgin olive oils from "Chétoui" cultivar. J. Oleo Sci. 65: 533-542.

EU Commission Regulation EEC. 1991. EU Commission Regulation EEC No. 2568/91 of 11 July 1991 on the characteristics of olive oil and olive-residue oil and on the relevant methods of analysis, and subsequent amendments. Official J. Eur. Com. L248: 1.

Fares, N., I. K. Jabri, S. Sifi and M. Abderrabba. 2016. Physical chemical and sensory characterization of olive oil of the region of Kairouan. J. Mater. Environ. Sci. 7: 2148-2154.

Gargouri, O. D., Y. B. Rouina, A. B. Mansour, G. Flamini, B. B. Rouina and M. Bouaziz. 2016. Comparative study of oil quality and aroma profiles from Tunisian olive cultivars growing in Sharian oasis using chemometric analysis. J. Oleo Sci. 65: 1033-1044.

Giuffrè, A. M., C. Zappia and M. Capocasale. 2017a. Effects of high temperatures and duration of heating on olive oil properties for food use and biodiesel production. J. Am. Oil Chem. Soc. 94: 819-830.

Giuffrè, A. M., C. Zappia and M. Capocasale. 2017b. Tomato seed oil for edible use: Cold break, hot break and harvest year effects. J. Food Process. Preservation. 41: e13309.

Giuffrè, A. M., M. Capocasale, C. Zappia and M. Poiana. 2017c. Influence of high temperature and duration of heating on the sunflower seed oil properties for food use and bio-diesel production. J. Oleo Sci. 66: 1193-1205.

Giuffrè, A. M., S. Tellah, M. Capocasale, C. Zappia, M. Latati, M. Badiani and S. M. Ounane. 2016. Seed oil from ten Algerian peanut landraces for edible use and biodiesel production. J. Oleo Sci. 65: 9-20.

Grati-Kamoun, N., F. L. Mahmoud, A. Rebaï, A. Gargouri, O. Panaud and A. Saar. 2006. Genetic diversity of Tunisian olive tree (Olea europaea L.) cultivars assessed by AFLP markers. Genet. Resour. Crop Ev. 53: 265-275.

Guerfel, M., Y. Ouni, A. Taamalli, D. Boujnah, E. Stefanoudaki and M. Zarrouk. 2009. Effect of location on virgin olive oils of the two main Tunisian olive cultivars. Eur. J. Lipid Sci. Technol. 111: 926-932.

Haddada, F. M., D. Krichène, H. Manai, I. Oueslati, D. Daoud and M. Zarrouk. 2008. Analytical evaluation of six monovarietal virgin olive oils from Northern Tunisia. Eur. J. Lipid Sci. Technol. 110: 905-913. 
Hassine, K. B., A. Taamalli, M. B. Slama, T. Khouloud, A. Kiristakis, C. Benincasa, E. Perri, D. Malouche, M. Hammami, S. Bornaz and N. Grati-Kammoun. 2015. Characterization and preference mapping of autochthonous and introduced olive oil cultivars in Tunisia. Eur. J. Lipid Sci. Technol. 117: 112-121.

Hlima, H. B., R. B. Ayed, K. Ennouri and S. Smaoui. 2017. Geographical discrimination of virgin olive oils from the Tunisian coasts by combining fatty acids and phenolic acids profiles within a multivariate analysis. J. Oleo Sci. 66: 963-971.

ISO 6886. 2016. Animal and Vegetable Fats and Oils - Determination of Oxidative Stability (Accelerated Oxidation Test). Geneva, Switzerland, p. 13.

ISO 9936. 2016. Animal and Vegetable Fats and Oils - Determination of Tocopherol and Tocotrienol Contents by High-Performance Liquid Chromatography. Geneva, Switzerland, p. 16.

Issaoui, M., H. Chehab, F. Attia, G. Flamini, B. Mechri, M. Braham, C. P. Luigi and M. Hammami. 2012. Influence of two maturation stages and three irrigation regimes on Chétoui olive oil quality. Afr. J. Agric. Res. 6: 4124-4130.

Issaoui, M., S. Dabbou, A. Echbili, I. Rjiba, N. Gazzah, A. Trigui and M. Hammami. 2007. Biochemical characterization of some Tunisia virgin olive oils obtained from different cultivars growing in Sfax National Collection. J. Food Agric. Environ. 5: 17-21.

Kalantzakis, G., G. Blekas, K. Pegklidou and D. Boskou. 2006. Stability and radical-scavenging activity of heated olive oil and other vegetable oils. Eur. J. Lipid Sci. Technol. 108: 329-335.

Kirkpatrick, S., C. D. Gelatt and M. P. Vecchi. 1983. Optimization by simulated annealing. Science. 220: 671-680.

Kotti, F., E. Chiavaro, L. Cerretani, C. Barnaba, M. Gargouri and A. Bendini. 2009. Chemical and thermal characterization of Tunisian extra virgin olive oil from Chetoui and Chemlali cultivars and different geographical origin. Eur. Food Res. Technol. 228: 735-742.

Krichene, D., W. Taamalli, D. Daoud, M. D. Salvador, G. Fregapane and M. Zarrouk. 2007. Phenolic compounds, tocopherols and other minor components in virgin olive oils of some Tunisian varieties. J. Food Biochem. 31: 179-194.

Laroussi-Mezghani, S., P. Vanloot, J. Molinet, N. Dupuy, M. Hammami, N. Grati-Kamoun and J. Artaud. 2015. Authentication of Tunisian virgin olive oils by chemometric analysis of fatty acid compositions and NIR spectra. Comparison with Maghrebian and French virgin olive oils. Food Chem. 173: 122-132.

Laroussi-Mezghani, S., Y. Le Dréau, J. Molinet, M. Hammami., N. Grati-Kamoun and J. Artaud. 2016. Biodiversity of Tunisian virgin olive oils: Varietal origin classification according to their minor compounds. Eur. Food Res. Technol. 242: 1087-1099.

Loubiri, A., A. Taamalli, N. Talhaoui, S. N. Mohamed, A. S. Carretero and M. Zarrouk. 2017. Usefulness of phenolic profile in the classification of extra virgin olive oils from autochthonous and introduced cultivars in Tunisia. Eur. Food Res. Technol. 243: 467-479.

Mansour, A. B., B. Gargouri, G. Flamini and M. Bouaziz. 2015. Effect of agricultural sites on differentiation between Chemlali and Neb Jmel olive oils. J. Oleo Sci. 64: 381-392.
Marone, E., E. Masi, C. Taiti, C. Pandolfi, N. Bazihizina, E. Azzarello, P. Fiorino and S. Mancuso. 2018. Sensory, spectrometric (PTRToF-MS) and chemometric analyses to distinguish extra virgin from virgin olive oils. J. Food Sci. Technol. 54: 1368-1376.

Martens, H. A. and P. Dardenne. 1998. Validation and verification of regression in small data sets. Chemometr. Intell. Lab. Syst. 44: 99-121.

Mohamed, B. M., F. Guasmi, S. B. Ali, F. Radhouani, J. Faghim, T. Triki, N. Grati-Kammoun, C. Baffi, L. Lucini and C. Benincasa. 2018a. The LC-MS/MS characterization of phenolic compounds in leaves allows classifying olive cultivars grown in south Tunisia. Biochem. Syst. Ecol. 78: 84-90.

Mohamed, B. M., G. Rocchetti, D. Montesano, S. B. Ali, F. Guasmi, N. Grati-Kammoun, and L. Lucini. 2018b. Discrimination of Tunisian and Italian extra-virgin olive oils according to their phenolic and sterolic fingerprints. Food Res. Int. 106: 920-927.

Ouni, Y., G. Flamini and M. Zarrouk. 2016. The chemical properties and volatile compounds of virgin olive oil from Oueslati variety: Influence of maturity stages in olives. J. Am. Oil Chem. Soc. 93: 1265-1273.

Slim, S., N. Rodrigues, L. G. Dias, A. C. A. Veloso, J. A. Pereira, S. Oueslati and A. M. Peres. 2017. Application of an electronic tongue for Tunisian olive oils' classification according to olive cultivar or physicochemical parameters. Eur. Food Res. Technol. 243: 1459-1470.

Souayah, F., N. Rodrigues, A. C. A. Veloso, L. G. Dias, J. A. Pereira, S. Oueslati and A. M. Peres. 2017. Discrimination of olive oil by cultivar, geographical origin and quality using potentiometric electronic tongue fingerprints. J. Am. Oil Chem. Soc. 94: 14171429.

Taamalli, A., A. M. Gomez-Caravaca, M. Zarrouk, A. Segura-Carretero and A. Fernandez-Gutierrez. 2010. Determination of apolar and minor polar compounds and other chemical parameters for the discrimination of six different varieties of Tunisian extra-virgin olive oil cultivated in their traditional growing area. Eur. Food Res. Technol. 231: 965-975.

Temine, S. B., B. Baccouri, W. Taamalli, L. Abaza, D. Daoud and M. Zarrouk. 2006. Location effects on oxidative stability of Chétoui virgin olive oil. J. Food Biochem. 30, 659-670.

Tena, N., A. Lazzez, R. Aparicio-Ruiz and D. L. García-González. 2007. Volatile compounds characterizing Tunisian chemlali and Chétoui virgin olive oils. J. Agric. Food Chem. 55: 7852-7858.

Thaipong, K., U. Boonprakob, K. Crosby, L. Cisneros-Zevallos and D. H. Byrne. 2006. Comparison of ABTS, DPPH, FRAP, and ORAC assays for estimating antioxidant activity from guava fruit extracts. J. Food Compos. Anal. 19: 669-675.

Venables, W. N. and B. D. Ripley. 2002. Modern Applied Statistics with $S$ (Statistics and Computing), $4^{\text {th }}$ ed. Springer, New York.

Yashin, A., Y. Yashin, J. Y. Wang and B. Nemzer. 2013. Antioxidant and antiradical activity of coffee. Antioxidants. 2: 230-245.

Youssef, O., F. Guido, D. Daoud and Z. Mokhtar. 2011. Effect of cultivar on minor components in Tunisia olive fruits cultivated in microclimate. J. Hortic. Forest. 3: 13-20. 